\title{
A CASA DA QUALIDADE - PRÁTICAS E DINÂMICAS PARA O PROCESSO DE ENSINO APRENDIZAGEM
}

DOI: 10.37702/2175-957X.COBENGE.2021.3754

Felipe Lopes Roberto - felipeiav269@gmail.com

Universidade Federal do Paraná

Rua São José de Arimatéia 140

81910-050 - Curitiba - PR

Maria do Carmo Duarte Freitas - carmemk2@gmail.com

Universidade Federal do Paraná

RUA SCHILLER 555

80050-260 - Curitiba - PR

Resumo: Objetivo: apresentar uma dinâmica para o ensino da ferramenta Quality Function Deployment - Desdobramento da Função Qualidade (QFD), para compreensão do seu uso e aplicação. Método: A proposta visa a aplicação da ferramenta QFD, assim como a elaboração da matriz, de modo empírico em uma situação real ou fictícia. Resultados: Como resultados têm-se a apresentação das etapas da dinâmica QFD. Para o desenvolvimento da mesma faz-se necessário a apresentação do cliente, logo em seguida sugere-se para esta dinâmica, a formação de equipes, projetando o compartilhamento de informações entre os integrantes. O docente deverá compartilhar um estudo de caso (fictício ou não), apresentando a problemática para a aplicabilidade da ferramenta (QFD). Depois de realizada a leitura, pelo docente, das informações do estudo de caso, os alunos deverão identificar os requisitos do cliente e do produto. Para esta etapa, os discentes poderão questionar-se a respeito da carência de informações no que se refere ao cliente. Para a próxima etapa, é necessária a definição de representação das relações fraca, mediana e forte. Na última etapa, o aplicador da dinâmica mostrará produtos com potencial para a resolução dos problemas expostos anteriormente pelo cliente. Conclusão: Conclui-se que a utilização de metodologias ativas promovem o protagonismo por parte do discente, assim como a tecnologia possibilita a ampliação de novos conhecimentos e a otimização das práticas de ensino. A aplicação de novas metodologias para o processo de ensino e aprendizagem exigirá dos docentes dos cursos de engenharia a criação de condições para a efetiva construção de conhecimento, objetivando despertar o interesse dos alunos em aulas presenciais ou no ambiente virtual. 


\section{(C) COBENGE

Palavras-chave: Desdobramento da Função Qualidade, Processo Ensino -Aprendizagem, Metodologias Ativas, Qualidade. 


\section{A CASA DA QUALIDADE - PRÁTICAS E DINÂMICAS PARA O PROCESSO DE ENSINO APRENDIZAGEM}

\section{INTRODUÇÃO}

No momento pandêmico, a educação ainda é constituída por características de um ensino tradicional, no qual os estudantes são vistos como sujeitos passivos no processo de ensino e aprendizagem, e os docentes são os detentores do saber. Consequentemente, o aluno perde o interesse pelas aulas, devido ao número reduzido de propostas objetivando mais atratividade para motivar os discentes a aprender e construir seu próprio conhecimento (NICOLA; PANIZ, 2016).

Saito e Santos (2014) ressaltam a importância da reflexão a respeito das práticas educacionais adequadas ao contexto do discente do século XXI. Apesar dessa temática estar sendo discutida em diversos locais do mundo, é notória a complexidade na modificação do processo de ensino. Debater as alternativas novas analisando a motivação e o interesse do estudante, poderá ser uma opção para elaboração do ambiente escolar. As práticas reflexivas e os encontros mais humanizados são maneiras de dinamizar o aprendizado dos alunos, possibilitando o entendimento em relação ao significado daquilo que o Estado, por intermédio da escola, quer ensinar.

O papel do docente, na visão de Tinoco, Peixoto e Luquetti (2019), é estimular o aluno em seu desenvolvimento e na procura pelo conhecimento. Esse profissional deverá ser preparado e adaptado a contextos novos, distante das peculiaridades do ensino tradicional quanto à abertura de novas práticas e participação ativa dos estudantes no processo de ensino e aprendizagem. Diante disso, a dinamicidade e a flexibilidade são características essencialmente presentes na identidade da profissão docente, permitindo assim, a construção de novas práticas pedagógicas.

Já Silveira et. al. (2019) explicam, por meio do seu estudo de aplicação da Sala de Aula Invertida nas aulas de cursos superiores de Computação, a necessidade de alteração no papel do docente devido à criação de cursos na Internet. Neste contexto, o professor deverá assumir o papel de orientador dos discentes no processo de aprendizagem, incentivando-os à pesquisa e ao desenvolvimento das atividades solicitadas. Para os autores, a motivação do aluno é o que promove o desenvolvimento satisfatório desses cursos, sendo primordial que o mesmo seja encorajado a seguir as diretrizes propostas no curso apresentado.

O ganho no processo de ensino e aprendizagem dos alunos é gerado por meio do uso de diversos recursos. O surgimento da motivação e interesse dos alunos desponta a partir do momento que é aflorada a vontade de construção de conhecimento. A motivação é igualmente despertada nos docentes tornando-os mais propensos a incentivar os estudantes para a concretização do processo de construção de conhecimento (NICOLA e PANIZ, 2016).

Nicola e Paniz (2016) relatam que a utilização de diferentes recursos didáticos promove a otimização do processo educativo, assim como permite ao professor refletir sobre novos cenários e possibilidades para a construção das aulas.

No contexto da pandemia, as instituições precisaram se reinventar, deixando em segundo plano a inovação, para priorizar a adaptação a um novo cenário constituído pela elaboração de aulas no ambiente virtual. Para Borba (2020), o docente surge como protagonista dessas mudanças, pois para ele os professores:

Tiveram que repensar seus planos de ensino, suas dinâmicas de aula, para um ambiente remoto. Na maioria dos casos, especialmente nas instituições privadas, o apoio para esta transformação foi, em um primeiro momento, focado nas tecnologias. Os 
docentes aprenderam a usar plataformas da webconferência, ferramentas de gravação de aulas, entre tantas outras. O trabalho se multiplicou, e o desafio de manter o aluno engajado em seu processo de aprendizagem, se tornou ainda mais intenso (BORBA, 2020, p. 36).

É diante desta realidade repleta de desafios, sem a possibilidade de aula presencial, que os docentes repensam suas práticas e dinâmicas, como a que será apresentada na próxima seção, objetivando a melhora no processo de ensino e aprendizagem.

Diante desse contexto, a pesquisa tem o objetivo de apresentar uma dinâmica para o ensino da ferramenta Quality Function Deployment - Desdobramento da Função Qualidade (QFD), para compreensão do seu uso e aplicação. Como forma de validar a dinâmica, desenvolveu-se a aplicação com alunos de graduação de um curso do ensino superior de uma universidade pública brasileira. Destaca-se que o tema é abordado na maioria dos cursos de engenharia.

\section{CASA DA QUALIDADE - (QUALITY FUNCTION DEPLOYMENT - DESDOBRAMENTO DA FUNÇÃO QUALIDADE)}

O mercado em um mundo globalizado necessita priorizar o cliente e dispõe a ele diversos produtos e serviços, o que gera nas empresas a necessidade de desenvolver produtos que chamem a atenção dos clientes e sejam escolhidos (PASQUINI, 2013).

A informação e o conhecimento são essenciais para as empresas na corrida pela oferta de produtos com qualidade aos seus clientes, tornando-se ferramentas para a construção de um plano estratégico no mercado consumidor (SANTOS; BASTOS, 2017).

O cliente nesse ponto de vista recebe diversas ofertas de produtos e serviços de qualidade que priorizam seus desejos e necessidades e por este motivo faz-se necessário empregar ferramentas que favoreçam a compreensão a respeito dos verdadeiros interesses do cliente (BARTZ; MAIA, 2017).

A qualidade dos serviços e as ferramentas e técnicas são essenciais para o desenvolvimento dos produtos, sendo o acompanhamento e análise dos processos, seja o envolvimento na melhoria dos processos, resolução dos processos, compressão da necessidade e a mudança de experiências para melhorar os processos. Nessa perspectiva o Desdobramento da Função Qualidade (QFD) torna-se uma ferramenta importante na corrida do mercado (HONDA, 2017).

O desdobramento da função qualidade é utilizado em várias áreas já em meados dos anos 70, objetivando acelerar o processo de desenvolvimento de processos e produtos de forma mais eficaz, moldando os produtos de acordo com as principais necessidades dos clientes (DIAS, 2018).O QFD pode ser considerado uma técnica que é direcionada ao cliente, visando a inovação e aprimoramento dos produtos, a fim de tornar suas características pontos de controle de qualidade em sua fase de produção (DIAS, 2018).

Essa ferramenta compreende a transformação de dados em requisitos, com a retirada das principais características do produto a partir dos requisitos da relação entre eles. Esse processo advém da elaboração de diagramas na forma de matrizes e árvores no modo de relacionamento (CARPINETTI, 2012).

A importância da aprendizagem de sua aplicação e a temática desta proposta na forma de uma dinâmica que será descrita a seguir. 


\section{MATERIAIS E MÉTODO - DINÂMICA PARA O ENSINO DE QFD}

A proposta visa a aplicação da ferramenta QFD, assim como a elaboração da matriz, de modo empírico em uma situação real ou fictícia. Esta proposta poderá ser desenvolvida na sala de aula ou no ambiente virtual, objetivando de maneira simples, eficiente e de fácil entendimento, o melhor aprendizado dos acadêmicos. Para este propósito, foi criada uma dinâmica de ensino.

Com a finalidade de otimizar o aprendizado do discente, esta dinâmica foi idealizada para ser aplicada a diversas áreas do conhecimento. Contudo, deve-se adaptar esta prática a formação, habilidades e experiências dos alunos.

Para o desenvolvimento da dinâmica faz-se necessário a apresentação do cliente, expondo a problemática, as características do mesmo (que interferem na seleção do produto ou serviço) e os desejos (que estão relacionados ao produto ou serviço). É essencial que todas as características do cliente sejam evidenciadas. Para estimular o discente, no que concerne a captura dos requisitos do cliente, recomenda-se que os desejos do cliente sejam apresentados de modo superficial.

Como exemplo será apresentado um case na área de gestão da informação, em que o cliente (Empresa X), apresenta problemas com informações e serviços demandados de maneira incorreta. Diante deste cenário, os alunos deverão representar o profissional de gestão da informação, que buscará identificar os requisitos do cliente e do produto, com a finalidade de desenvolver a matriz QFD. No quadro 1 é apresentado os componentes da dinâmica do QFD.

QUADRO 01 - Componentes da Dinâmica - Graduandos dos cursos de administração, gestão da informação e engenharias

\begin{tabular}{|l|l|}
\hline Situação & $\begin{array}{l}\text { Cliente gostaria de um marketing adequado para auxiliar os usuários com } \\
\text { solicitações de informações de acordo com a sua demanda }\end{array}$ \\
\hline Cliente & Empresa X \\
\hline Público-alvo & $\begin{array}{l}\text { Estudantes de graduação dos cursos de administração, gestão da } \\
\text { informação e engenharias. }\end{array}$ \\
\hline Características do cliente & $\begin{array}{l}\text { A Empresa X tem como objetivo viabilizar um sistema de comunicação ágil e } \\
\text { eficiente entre o cidadão e a prefeitura de Curitiba, atendendo demandas de } \\
\text { informações e solicitações, principalmente da área de segurança, } \\
\text { confiabilidade e qualidade. Hoje, a Empresa X é um contact center que } \\
\text { atende a demanda dos cidadãos curitibanos através de ligações, com } \\
\text { algumas funcionalidades disponíveis no ambiente online. }\end{array}$ \\
\hline $\begin{array}{l}\text { Especificações do cliente } \\
\text { (Empresa X) }\end{array}$ & $\begin{array}{l}\text { Desenvolvimento de um produto ou serviço de informação focado em } \\
\text { solucionar problemas acerca das solicitaços encaminhadas de maneira } \\
\text { incorreta, que causam lentidão e retrabalho para o repasse de informações. } \\
\text { Além disso, destacaram que será lançado um aplicativo móvel para o } \\
\text { serviço, visando atender outra faixa de público (12 a } 25 \text { anos), desta forma, } \\
\text { entende-se que a demanda de serviços solicitados incorretamente poderá } \\
\text { criar mais um gargalo no fluxo de informações. }\end{array}$ \\
\hline
\end{tabular}

Fonte: Elaborado pelo autor (2021)

Sugere-se para esta dinâmica, a formação de equipes, projetando o compartilhamento de informações entre os integrantes. O docente deverá compartilhar um estudo de caso (fictício ou não), apresentando a problemática para a aplicabilidade da ferramenta (QFD). O case necessitará de um cliente, uma empresa ou o cliente da mesma, 
que apresentará o desejo por um produto ou serviço estipulado. Por meio de um texto serão discorridas as particularidades do cliente (determinantes para a seleção do produto) e os seus interesses (a respeito do produto). Os interesses do cliente poderão ser evidenciados de modo superficial, com o intuito de estimular a cognição dos discentes.

Depois de realizada a leitura, pelo docente, das informações do estudo de caso, os alunos deverão identificar os requisitos do cliente e do produto. Esta etapa, será realizada no ambiente virtual, utilizando a ferramenta Jamboard (ou outra ferramenta escolhida pelo docente), sendo um quadro interativo desenvolvido pelo Google, possibilitando a interação entre os discentes. É fundamental para cada equipe a disposição de um espaço no quadro interativo para a inserção de informações referentes aos requisitos. Com a finalidade de monitorar as atividades designadas, o aplicador da dinâmica deverá construir uma tabela esclarecendo a ordem, o tempo e os materiais primordiais para a atividade. 
TABELA 02 - Atividades estabelecidas para a dinâmica

\begin{tabular}{|c|c|c|c|c|}
\hline Ordem & Tempo & Ação & Objetivos & Descrição \\
\hline 1 & $\begin{array}{l}1 \text { semana } \\
\text { antes da } \\
\text { aplicação }\end{array}$ & $\begin{array}{l}\text { Elaboração do material para a } \\
\text { dinâmica }\end{array}$ & $\begin{array}{l}\text { Criar o material } \\
\text { adequado para o seu } \\
\text { público }\end{array}$ & $\begin{array}{l}\text { O discente deverá interagir com a ferramenta escolhida, selecionando as } \\
\text { formas e ícones que criarão a matriz QFD para a aplicação da dinâmica. É } \\
\text { necessário que o professor esteja preparado para fazer ediç̃̃es na } \\
\text { ferramenta, pois poderão surgir dúvidas no decorrer da atividade. }\end{array}$ \\
\hline 2 & 2 minutos & Introdução ao QFD & $\begin{array}{l}\text { Expor os principais } \\
\text { conceitos do QFD }\end{array}$ & $\begin{array}{l}\text { Apresentar o conceitos de QFD (Quality Function Deployment - } \\
\text { Desdobramento da Função Qualidade) com a finalidade de demonstrar a } \\
\text { funcionalidade e importância da temática. }\end{array}$ \\
\hline 3 & 2 minutos & Formação dos grupos & $\begin{array}{l}\text { Compartilhamento de } \\
\text { informações entre os } \\
\text { participantes }\end{array}$ & $\begin{array}{l}\text { O aplicador deverá orientar os alunos na formação de equipes para } \\
\text { realização da dinâmica. O intuito é oportunizar a interação entre os colegas } \\
\text { de equipe, através da troca de informações e tomada de decisão durante a } \\
\text { atividade. }\end{array}$ \\
\hline 4 & 2 minutos & $\begin{array}{l}\text { Explicação geral do } \\
\text { funcionamento da dinâmica }\end{array}$ & $\begin{array}{l}\text { Discorrer sobre os } \\
\text { estágios da dinâmica }\end{array}$ & $\begin{array}{l}\text { O discente deverá fazer um overview sobre todas as etapas que compõem } \\
\text { a criação da matriz QFD, com o objetivo de apresentar as os processos de } \\
\text { desenvolvimento da atividade }\end{array}$ \\
\hline 5 & 2 minutos & $\begin{array}{l}\text { Explicação das funcionalidades da } \\
\text { ferramenta utilizada }\end{array}$ & $\begin{array}{l}\text { Apresentar as } \\
\text { características da } \\
\text { ferramenta } \\
\text { selecionada }\end{array}$ & $\begin{array}{l}\text { Demonstrar as principais funcionalidades da ferramenta para a elaboração } \\
\text { da matriz. O professor mostrará formas de inserir, copiar, mover, editar e } \\
\text { apagar o conteúdo da ferramenta. }\end{array}$ \\
\hline 6 & 2 minutos & Apresentação do estudo de caso & $\begin{array}{l}\text { Realizar a leitura do } \\
\text { estudo de caso para } \\
\text { os discentes }\end{array}$ & $\begin{array}{l}\text { Exemplo de estudo de caso elaborado para a dinâmica: } \\
\text { A empresa x, tem como objetivo viabilizar um sistema de comunicação ágil } \\
\text { e eficiente entre o cidadão e a Prefeitura de Curitiba. Um dos principais } \\
\text { problemas é a inexistência de marketing direcionado para o público de } \\
\text { crianças e adolescentes. A primeira etapa foi a escolha do local para a } \\
\text { pesquisa para a aplicação do questionário com o público-alvo tendo entre } \\
12 \text { e } 25 \text { anos de idade. Nesta pesquisa, determinou-se como opções de } \\
\text { produtos, cartilhas, cartazes, panfletos, e-book e post no facebook. Por } \\
\text { meio dos resultados do questionário, os usuários apontaram suas } \\
\text { preferências a respeito do produto. Para que a equipe produzisse o } \\
\text { produto de forma satisfatória, o mesmo deveria ser adequado ao público, } \\
\text { com a ergonomia correta, no formato digital com recursos visuais e } \\
\text { elementos autoexplicativos. Também foram indicados a usabilidade e } \\
\text { grande alcance de usuários. Partindo do resultado da pesquisa com o }\end{array}$ \\
\hline
\end{tabular}




\begin{tabular}{|c|c|c|c|c|}
\hline & & & & $\begin{array}{l}\text { usuário, a equipe estabeleceu que o seu produto necessitaria de material } \\
\text { de qualidade com um conteúdo visual, textual e estrutura dos elementos } \\
\text { adequada e uma arquitetura do produto de acordo com a expectativa do } \\
\text { usuário. Pensou-se também que a fonte do conteúdo textual deveria ser } \\
\text { confiável. Refletindo sobre a identidade visual do produto, a equipe } \\
\text { percebeu a importância dos elementos visuais, assim como a paleta de } \\
\text { cores para demonstrar a relação com a marca. }\end{array}$ \\
\hline 7 & 5 minutos & Coleta dos requisitos do cliente & $\begin{array}{l}\text { Identificar os requisitos } \\
\text { do cliente }\end{array}$ & $\begin{array}{l}\text { Orientar os alunos a selecionar os requisitos do cliente apresentados no } \\
\text { estudo de caso compartilhado. } \\
\text { - Visualmente agradável; } \\
\text { - Engraçado; } \\
\text { - Ergonomia adequada; } \\
\text { - Lácil acesso; } \\
\text { - Didguagem apropriada e; }\end{array}$ \\
\hline 8 & 1 minuto & $\begin{array}{l}\text { Orientação para a inserção dos } \\
\text { requisitos do cliente no quadro } \\
\text { interativo }\end{array}$ & $\begin{array}{l}\text { Demonstrar as formas } \\
\text { de inserção dos } \\
\text { requisitos no quadro } \\
\text { interativo }\end{array}$ & $\begin{array}{l}\text { Ensinar os alunos a inserir, editar ou apagar, no quadro interativo, os } \\
\text { requisitos do cliente identificados durante a leitura do estudo de caso. }\end{array}$ \\
\hline 9 & 2 minutos & $\begin{array}{l}\text { Análise da coleta realizada pelos } \\
\text { discentes (requisitos do cliente) }\end{array}$ & $\begin{array}{l}\text { Identificar as } \\
\text { dificuldades dos } \\
\text { alunos }\end{array}$ & $\begin{array}{l}\text { Monitorar e identificar as principais dificuldades referentes a essa etapa. É } \\
\text { possível que muitos alunos demonstrem dificuldades em relação a } \\
\text { identificação dos requisitos, devido a inexperiência nessa ação. Portanto, o } \\
\text { discente deverá demonstrar a maneira adequada de identificar os } \\
\text { requisitos, para que em sequência os alunos possam reproduzir suas } \\
\text { ações, melhorando assim, sua experiência na atividade. }\end{array}$ \\
\hline 10 & 5 minutos & Coleta dos requisitos dos produto & $\begin{array}{l}\text { Identificar os requisitos } \\
\text { do produto }\end{array}$ & $\begin{array}{l}\text { Orientar os alunos a selecionar os requisitos do produto apresentados no } \\
\text { estudo de caso compartilhado. } \\
\text { - Cores; } \\
\text { - Caracteres; } \\
\text { - Personagens; } \\
\text { - Pixels; } \\
\text { - Quadros; } \\
\text { - Publicações e; } \\
\text { - Tamanho da fonte. }\end{array}$ \\
\hline 11 & 1 minuto & Orientação para a inserção dos & Demonstrar as formas & Ensinar os alunos a inserir, editar ou apagar, no quadro interativo, os \\
\hline
\end{tabular}

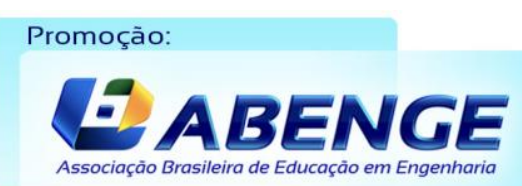

Realização:

\section{$\mathrm{U} F \mathrm{~m} \mathrm{G}$}

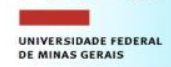




\begin{tabular}{|c|c|c|c|c|}
\hline & & $\begin{array}{l}\text { requisitos do produto no quadro } \\
\text { interativo }\end{array}$ & $\begin{array}{l}\text { de inserção dos } \\
\text { requisitos no quadro } \\
\text { interativo }\end{array}$ & requisitos do produto identificados durante a leitura do estudo de caso. \\
\hline 12 & 2 minutos & $\begin{array}{l}\text { Avaliação da coleta feita pelos } \\
\text { alunos (requisitos do produto) }\end{array}$ & $\begin{array}{l}\text { Analisar as } \\
\text { dificuldades dos } \\
\text { discentes }\end{array}$ & $\begin{array}{l}\text { O aplicador deverá monitorar e identificar as principais dificuldades } \\
\text { referentes a essa etapa. É provável que muitos alunos demonstrem } \\
\text { incompreensão no ato de identificação dos requisitos do produto, } \\
\text { apresentando-os de modo qualitativo. Portanto, o discente deverá } \\
\text { demonstrar a maneira adequada de transformar em qualitativos os } \\
\text { requisitos do produto, para que em sequência os alunos possam reproduzir } \\
\text { suas ações, otimizando sua experiência com a dinâmica. }\end{array}$ \\
\hline 13 & 2 minutos & $\begin{array}{l}\text { Expor o grau de importância dos } \\
\text { requisitos do cliente }\end{array}$ & $\begin{array}{l}\text { Indicar o grau de } \\
\text { importância dos } \\
\text { requisitos no quadro } \\
\text { interativo }\end{array}$ & $\begin{array}{l}\text { O professor deverá explicar que cada requisito terá um grau de importância } \\
\text { para o usuário, sendo identificados com pesos que irão variar de } 1 \text { a } 5 \text {, } \\
\text { sendo o } 5 \text { o mais importante e } 1 \text { o menos importante na visão do mesmo. }\end{array}$ \\
\hline 14 & 2 minutos & $\begin{array}{l}\text { Explicação sobre as relações } \\
\text { entre requisitos do cliente e do } \\
\text { produto e os valores utilizados }\end{array}$ & $\begin{array}{l}\text { Identificar os níveis de } \\
\text { relação forte, média e } \\
\text { fraca }\end{array}$ & $\begin{array}{l}\text { Apontar no quadro interativo o nível de relação entre os requisitos do } \\
\text { cliente e do produto. O discente deverá enfatizar que determinadas } \\
\text { relações não apresentam relação entre elas, pois uma não afetará a outra. } \\
\text { Caso isso não fique explícito, os alunos poderão preencher a matriz de } \\
\text { maneira incorreta. }\end{array}$ \\
\hline 15 & 3 minutos & Soma das relações & $\begin{array}{l}\text { Descobrir o requisito } \\
\text { mais importante }\end{array}$ & $\begin{array}{l}\text { Orientar os alunos a realizar a soma das relações entre o requisito do } \\
\text { produto e do cliente, para que consequentemente seja descoberto os } \\
\text { requisitos mais significativos. }\end{array}$ \\
\hline 16 & 5 minutos & $\begin{array}{l}\text { Selecionar o produto de } \\
\text { informação }\end{array}$ & $\begin{array}{l}\text { Brainstorming entre os } \\
\text { integrantes de cada } \\
\text { equipe }\end{array}$ & $\begin{array}{l}\text { Devido o público-alvo ser composto por adolescentes de } 12 \text { a 25, os } \\
\text { produtos de informação selecionados para esse estudo de caso foram: } \\
\text { Post no facebook; E-book; Cartilha; Flyer; Cartilhas }\end{array}$ \\
\hline 17 & $\begin{array}{l}10 \\
\text { minutos }\end{array}$ & Debater acerca da dinâmica & $\begin{array}{l}\text { Instigar os discentes a } \\
\text { apresentar seus } \\
\text { questionamentos, } \\
\text { elogios e sugestões }\end{array}$ & $\begin{array}{l}\text { Conduzir um debate construtivo entre docente e discente sobre a dinâmica. } \\
\text { Descobrir os pontos positivos e negativos relatados pelos discentes. Sanar } \\
\text { todas as dúvidas expostas pelo alunos. Solicitar sugestões para a } \\
\text { otimização da aplicação da dinâmica. }\end{array}$ \\
\hline
\end{tabular}

Fonte: Elaborado pelo autor (2021)

\section{Promoção:

Realização:

\section{U F $m$ G

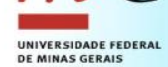


Para a etapa de coleta dos requisitos do cliente e do produto, os discentes poderão questionar-se a respeito da carência de informações no que se refere ao cliente. A falta de informações é um ato intencional para promover o senso crítico do estudante. Desta forma, entende-se que a compreensão das razões implícitas às informações de um texto, da mesma forma que a ponderação quanto a justificativas que fundamentam a adesão a tal ponto de vista, são meios que enriquecem a produção de textos e o florescimento do senso crítico. Entretanto, faz-se necessária a adequação de procedimentos, que permitam ao estudante uma metodologia de investigação (SILVA, 2013).

Como consequência dos questionamentos, o professor deverá explicar o propósito da etapa anterior, evidenciando as adversidades do processo de coleta dos requisitos e o modo adequado para concluir esse processo. A partir do momento em que os alunos finalizarem a etapa de coleta dos requisitos, deve-se orientá-los a repassar os itens para o quadro interativo. Os requisitos do produto deverão ser assinalados na parte superior da representação da matriz, bem como os requisitos do cliente que serão anotados à esquerda. Além disso, o discente deverá assinar os pesos dos requisitos do cliente, pretendendo demonstrar o grau de importância de cada requisito descrito. A figura 1 exemplifica o modelo de matriz QFD para a aplicação da dinâmica.

\section{FIGURA 01: Modelo de matriz QFD}

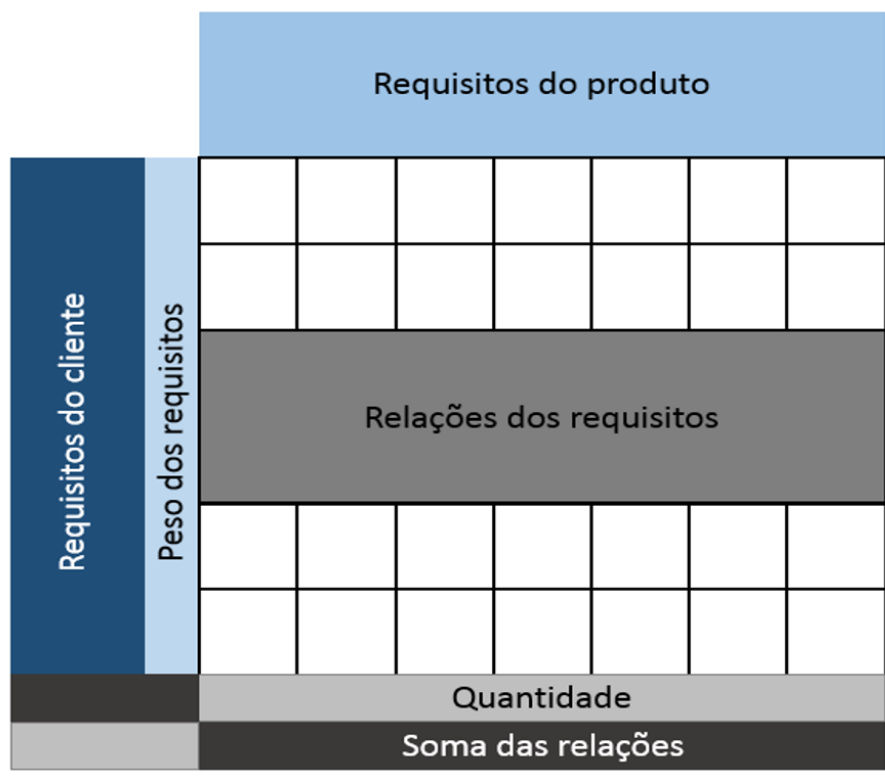

FONTE: Elaborado pelo autor (2021)

Para a próxima etapa, é necessária a definição de representação das relações fraca, mediana e forte. Neste exemplo, a forma quadrada representará a relação forte (valor $=9$ ), triângulo a relação média (valor $=3$ ) e o círculo simbolizará a relação fraca (valor $=1$ ). A escolha da representação das relações ficará a critério do aplicador da dinâmica, sendo possível a representação por meio de números e formas. As formas serão dispostas nas intersecções entre os requisitos do cliente e do produto, evidenciando suas relações. Após os discentes indicarem as relações entre os requisitos, o professor deverá orientá-los a somar os valores de cada forma em suas respectivas colunas, e anotar os resultados na parte inferior do quadro interativo. Somados os valores, os estudantes deverão indicar os requisitos que apresentaram o maior valor dentre os analisados. 
FIGURA 02: Gabarito para o estudo de caso

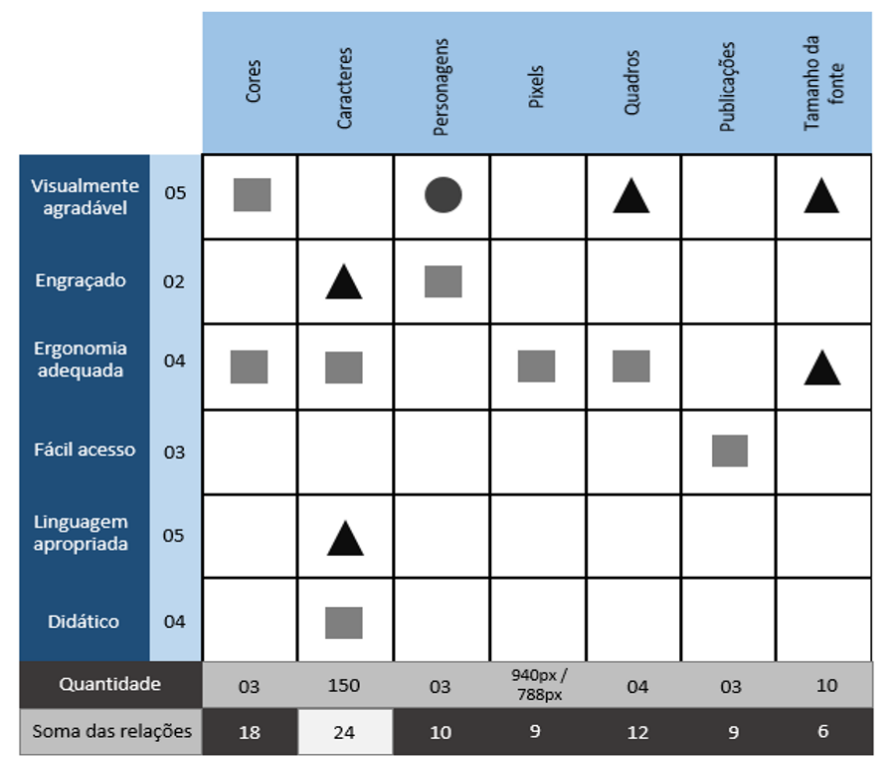

FONTE: Elaborado pelo autor (2021)

Na última etapa, o aplicador da dinâmica mostrará produtos com potencial para a resolução dos problemas expostos anteriormente pelo cliente. Os alunos deverão escolher o produto adequado, segundo suas convicções, justificando a escolha por meio de informações que sustentem essa decisão.

\section{CONSIDERAÇÕES FINAIS}

Nota-se que a utilização de metodologias ativas promovem o protagonismo por parte do discente, assim como a tecnologia possibilita a ampliação de novos conhecimentos e a otimização das práticas de ensino. A aplicação de novas metodologias para o processo de ensino e aprendizagem exigirá dos docentes dos cursos de engenharia a criação de condições para a efetiva construção de conhecimento, objetivando despertar o interesse dos alunos em aulas presenciais ou no ambiente virtual.

Devido ao contexto de pandemia, percebe-se que essas metodologias foram impulsionadas, pois a maioria das instituições buscou a elaboração de atividades remotas ou intensificando o uso das plataformas virtuais através da modalidade de educação a distância. Portanto, é notória a importância do uso e aplicabilidade dessa modalidade de ensino, com a intenção de minimizar os prejuízos ocasionados aos discentes, devido a pandemia, além de possibilitar um ambiente educacional que incentiva o docente na criação do conhecimento. 


\section{REFERÊNCIAS}

BARTZ, Silvia Regina Klein; MAIA, Fabio Luis da Silva. Aplicação da casa da qualidade no processo de desenvolvimento e melhoria de serviços: desdobrando a voz dos clientes de uma clínica médica. Revista Eletrônica de Administração (Online), v. 16, n.1, ed. 30, Jan-Jun 2017. Disponível em:http://periodicos.unifacef.com.br/index.php/rea/article/view/1149. Acesso em: 02 fev. 2021.

BARROS, Murillo Vetroni. Aplicação do método QFD como ferramenta da qualidade: um estudo de caso no estabelecimento alimentício da utfpr campus ponta grossa. XXXVII Encontro nacional de engenharia de produção. Joinville, SC, Brasil, 10 a 13 de outubro de 2017. Disponível em:

http://www.abepro.org.br/biblioteca/TN_STO_239_389_31467.pdf. Acesso em: 02 mar. 2021.

BORBA, Gustavo severo de. A transformação do ensino superior não está na tecnologia, está nos professores. In: COSTIN, Claudia et al. A escola na pandemia : 9 visões sobre a crise do ensino durante o coronavírus. 1. ed., Porto Alegre, , 2020. Disponível em: http://www.unisinos.br/institutoinovacao/wp-content/uploads/2020/09/ebook-a-escola-napandemia-com.pdf. Acesso em: 29 abr. 2021.

CARPINETTI, Luiz Cesar Ribeiro. Gestão da Qualidade. Atlas, São Paulo, 2010.

\section{DIAS, Patrícia Alexandra Andrade. Aplicação da Casa da Qualidade no}

Desenvolvimento e Aperfeiçoamento de Dispositivos de Monitorização de Glicose em Jovens Adultos com Diabetes tipo 1. 2018. 176f. Dissertação (Mestrado em Engenharia Biomédica) Instituto Politécnico de Lisboa. Instituto Superior de Engenharia de Lisboa. Escola Superior de Tecnologia da Saúde de Lisboa. Lisboa, 2018. Disponível em: https://repositorio.ipl.pt/handle/10400.21/10836. Acesso em: 08 mar.2021

DUARTE, Luiz Carlos da Silva; DANILEVICZ, Ângela de Moura Ferreira; CATEN, Carla Ten. Desdobramento da função qualidade: caso dos laboratórios de metrologia e ensaios da Unijuí. ENEGEP. 2001. Disponível em:

http://www.abepro.org.br/biblioteca/enegep2001_tr26_0297.pdf. Acesso em: 07 mar. 2021.

GARVER, Michel S. Improving the house of quality with maximum difference scaling. International Journal of Quality \& Reliability Management, n. 29, v. 5, pp. 576-594, 2012. Disponível em: https://doi.org/10.1108/02656711211230535. Acesso em: 11 mar.2021.

HONDA, Ana Carolina. Aplicação de ferramentas de gestão da qualidade em ambiente de serviços hospitalares: Estudo de medidas de melhoria em Santa Casa de Misericórdia do estado de São Paulo. 2017. 161 f. Escola de Engenharia de São Carlos, Departamento de Engenharia de Produção, Universidade de São Paulo, São 
Carlos, 2017. Disponível em: https://teses.usp.br/teses/disponiveis/18/18156/tde21122017-112044/pt-br.php. Acesso em: 08 mar. 2021.

MARTINS, Vitor William Batista; FILHO, Hélio Raymundo Ferreira; SOARES, Delcio Cravo; SANTOS, Nayéslie Cristine Brandão.Utilização do desdobramento da função qualidade - QFD para análise e proposta de melhoria no serviço de transporte público. Sistemas \& Gestão, v. 11, pp. 31-48, 2016. Disponível em: https://www.revistasg.uff.br/sg/article/view/783/408. Acesso em: 03 mar. 2021.

ODORCZYK, Ricardo Siebenrok ;FREITAS, Maria do Carmo DuarteDinâmica para o ensino da ferramenta desdobramento da função qualidade (QFD). XV SEPROSUL Simposio de Ingeniería de la Producción Sudamericano,Agosto/Septiembre de 2015. Disponível em:

https://www.researchgate.net/publication/281748473_DINAMICA_PARA_O_ENSINO_DA FERRAMENTA_DESDOBRAMENTO_DA_FUNCAO_QUALIDADE_QFD. Acesso em: 11 mar.2021.

PASQUINI, Nilton Cesar. Desdobramento da Função da Qualidade (QFD) conceitos e aplicações. Revista Qualidade Emergente, 2013, v.5 n.1: 19-37, Disponível em: https://revistas.ufpr.br/qualidade/article/view/34711. Acesso em: 07 mar. 2021.

SANTOS, Fernanda dos; BASTOS, Lia Caetano. Casa da qualidade e qualidade da informação: revisão sistemática. Perspectivas em Ciência da Informação, v.22, n.1, p.100-111, jan./mar. 2017. Disponível em: https://www.scielo.br/scielo.php?pid=S141399362017000100100\&script=sci_abstract\&tlng=pt. Acesso em: 08 mar. 2021.

SILVA, Elisabeth Ramos da. O desenvolvimento do senso crítico no exercício de identificação e escolha de argumentos. Rev. Brasileira de Lingüística Aplicada, v.3, n .l, 57-184, 2003. Disponível em: https://www.scielo.br/pdf/rbla/v3n1/05.pdf. Acesso em: 22 fev. 2021.

TSAI, Kuen-Horng et al. Application of Quality Function Deployment in Design of Mobile Assistive Devices. Journal of Medical and Biological Engineering, v.28, n. 2, pp. 8793, 2008.

NICOLA, Jéssica Anese; PANIZ, Catiane Mazocco. A importância da utilização de diferentes recursos didáticos no ensino de biologia. Infor, Inov. Form., Rev. NEaD-Unesp, São Paulo, v. 2, n. 1, p.355-381, 2016. Disponível em:

https://ojs.ead.unesp.br/index.php/nead/article/view/infor2120167. Acesso em: 29 abr. 2021.

SAITO, Cecilia Noriko Ito; SANTOS, Roger. Práticas educacionais dinâmicas: potencialidades criativas e investigações. Seminário Internacional de Educação Superior. Formação e Conhecimento. 2014. Disponível em:

https://unisos.uniso.br/publicacoes/anais eletronicos/2014/1 es formacao de professore s/13.pdf. Acesso em: 29 Abr. 2021.

SILVEIRA, Sidnei Renato et al. Educação a Distância, Sala de Aula Invertida e Aprendizagem baseada em problemas: Possibilidades para o ensino de programação de computadores utilizando metodologias ativas de aprendizagem. In: Educação no Século 
XXI.Volume 36. Tecnologias. Belo Horizonte: Poisson. 2019. pag. 67- 75. Disponível em:

https://www.poisson.com.br/livros/educacao/volume36/Educacao no seculoXXI vol36.pdf . Acesso em: 29 abr. 2021.

TINOCO, Dhienes Charla Ferreira et al. Desafios e perspectivas da prática docente frente às tecnologias da informação e comunicação. In: Educação no Século XXI.Volume 36.

Tecnologias. Belo Horizonte. Poisson. 2019.p. 76-81. Disponível em:

https://www.poisson.com.br/livros/educacao/volume36/Educacao no seculoXXI vol36.pdf

. Acesso em: 29 abr. 2021.

\title{
QUALITY FUNCTION DEPLOYMENT - PRACTICES AND DYNAMICS FOR THE TEACHING LEARNING PROCESS
}

\begin{abstract}
Objective: to present a dynamic for teaching the Quality Function Deployment tool - Deployment of the Quality Function (QFD), to understand its use and application. Method: The proposal aims at the application of the QFD tool, as well as the elaboration of the matrix, empirically in a real or fictitious situation. Results: As results, the stages of the QFD dynamics are presented. For the development of the same, it is necessary to present the client, immediately afterwards it is suggested for this dynamic, the formation of teams, projecting the sharing of information between the members. The teacher must share a case study (fictitious or not), presenting the problem for the applicability of the tool (QFD). After reading through the case study information by the teacher, students should identify the customer and product requirements. For this stage, the students may question themselves about the lack of information regarding the client. For the next step, it is necessary to define weak, medium and strong relationships. In the last step, the dynamics applicator will show products with the potential to solve the problems previously exposed by the customer. Conclusion: It is concluded that the use of active methodologies promotes the protagonism on the part of the student, just as technology enables the expansion of new knowledge and the optimization of teaching practices. The application of new methodologies for the teaching and learning process will require the teachers of engineering courses to create conditions for the effective construction of knowledge, aiming to arouse the interest of students in faceto-face classes or in the virtual environment.
\end{abstract}

Keywords: Quality Function Deployment, Teaching- Learning Process, Active Methodologies, Quality. 